\title{
La historia sin fin(al feliz) de la paz en Colombia (o la crisis como estrategia de comunicación de gobierno)
}

\author{
Eugénie Richard \\ Universidad Externado de Colombia \\ richard.eugenie@uexternado.edu.co
}

\author{
Álvaro Llano \\ Universidad Externado de Colombia \\ alvaro.llano@est.vexternado.edu.co
}

Recibido: 16/5/2017 / Aceptado: 13/9/2017

doi: 10.26439/contratexto2017.n028.1539

\begin{abstract}
Resumen. Esta investigación propone analizar las lógicas narrativas alrededor del tema de la paz usadas por parte del gobierno y de la oposición entre el 2002 y el 2016, identificando actantes, esquemas narrativos y estrategias discursivas. Se trata de mirar cuál ha sido la historia que le ha dado o le ha restado legitimidad a la paz en Colombia, y cómo esta se ha alimentado y ha perpetuado siempre una crisis. Para ello, se ha hecho un especial enfoque en las campañas presidenciales entre el 2002 y el 2014, y en la campaña para el plebiscito por la paz del 2016, desde la óptica de varios narradores: los políticos, la propaganda y la televisión.

Palabras clave: Colombia / comunicación de gobierno / proceso de paz / marketing político / storytelling / semiótica
\end{abstract}




\title{
Peace in Colombia: A Story without (a Happy) ending (or Crisis as a Governmental Communication Strategy)
}

\begin{abstract}
Aвstract. The research proposes to analyze the narrative logics around the peace theme used by the government and the opposition between 2002 and 2016, identifying actants, narrative schemes and discursive strategies. It is a matter of looking at the history that has given or has undermined legitimacy to the peace in Colombia, and how this history has been nourished perpetuating a crisis. Therefore, the research focuses on the presidential campaigns between 2002 and 2014 and in the campaign for the 2016 peace plebiscite, from the perspective of several narrators: politicians, propaganda and television.

Keywords: Colombia / governmental communication / peace process / political marketing / storytelling / semiotic
\end{abstract}




\section{Introducción}

\section{Contexto}

$\mathrm{E}$

1 escenario de crisis ha sido recurrente en Colombia cuando se habla de paz. En los quince últimos años, se dieron dos procesos de paz, cuatro elecciones presidenciales y un referéndum; todos giraron alrededor del tema de la paz y de la posible crisis que significaría vivir sin ella, o incluso, en ella. Como lo recuerdan Uribe y Rincón (2016):

Después de más de medio siglo de conflicto armado con las FARC ${ }^{1}$, el discurso presidencial se ha centrado en el rumbo que debe tomar el país con respecto a este tema: Pastrana ganó las elecciones de 1998 prometiendo la Paz. Uribe Vélez ganó y gobernó durante ocho años con la idea de ganar la guerra contra el "terrorismo" llamado FARC. Santos ganó en el 2010 con un discurso de guerra. Sin embargo, cuando llegó al poder, cambió de posición y se concentró en el asunto de "la paz" o diálogos con las FARC. La paz se convirtió en el centro del debate político y, por eso, muchos de los candidatos decidieron emplear este tema bandera en su campaña.

Recordemos que, en el año 2002, el exgobernador de la región de Antioquia, Álvaro Uribe, llegó al poder presentándose como el hombre providencial que venía a poner un punto final a la crisis generada por el fracaso de los diálogos de paz de El Caguán entre el presidente Pastrana y los representantes de la guerrilla marxista de las FARC-EP ${ }^{2}$. Durante sus ocho años de gobierno, Uribe le dio continuidad a esa historia, que se alimentó de un escenario de crisis permanente y que requería unos enemigos encarnados por la guerrilla y un héroe, el presidente, para acabar con ellos. Esta narrativa impregnó los imaginarios y explica por qué los nuevos diálogos de paz que instauró Juan Manuel Santos en el 2012 con los voceros de la guerrilla en La Habana (Cuba) fueron interpretados por los uribistas como una traición. El nuevo presidente Santos era el responsable del retorno de la crisis por la entrega del país a sus enemigos y por renegar de los avances de la política de seguridad democrática de su antiguo mentor.

De su lado, Santos compuso su propia historia, intentando imponerse desde el 2012 como el presidente de la paz; este tema ha ocupado gran parte de su narrativa gubernamental. Su reelección en el 2014, que se basó en la crisis que generaría el abandono del proceso de paz, pareció significar la victoria del relato oficial sobre el de la oposición; pero, dos años después, la victoria del No en el plebiscito para la ratificación de los Acuerdos de La Habana por parte de los colombianos originó un nuevo escenario de crisis para el presidente

1 Fuerzas Armadas Revolucionarias de Colombia.

2 Fuerzas Armadas Revolucionarias de Colombia-Ejército del Pueblo. 
que había hecho de este tema su principal bandera de gobierno.

Adicionalmente, la fastuosa puesta en escena de la firma final de los acuerdos de paz en Cartagena y el framing que se utilizó para su cobertura cobraron una significación particular. La importancia que se dio a la figura de Rodrigo Londoño, comandante de la guerrilla, y a la presencia de jefes de Estados de izquierda (Venezuela y Cuba) durante el evento motivó una lectura de los hechos según la cual la guerrilla era la victoriosa del proceso de paz, y asumía una actitud prepotente frente a un Estado que había cedido a todas sus exigencias. Esa lectura fue la que causó un nuevo escenario de crisis gubernamental, que entraba en contradicción con la narración santista y le daba la razón a la lógica argumentativa del uribismo.

Por fin, las historias que propusieron santistas y uribistas durante la campaña para el plebiscito por la paz del 2016 para ratificar lo acordado en La Habana fueron antagónicas: mientras la oposición argumentaba que Santos quería firmar la paz a cualquier costo y que la impunidad iba a ser el precio que pagaría toda la sociedad colombiana, el gobierno intentó, sin éxito, convencer de que la firma de los acuerdos era el símbolo de una nueva historia, sinónima de un mejor futuro. Así, a pesar de la culminación exitosa del proceso de La Habana, este fue interpretado por la mayoría de los colombianos como una derrota del bien contra el mal.
Retrospectivamente, resulta interesante analizar las historias que se crearon alrededor del tema de la paz por parte del gobierno y de la oposición entre el 2002 y el 2016, identificando actantes, esquemas narrativos y estrategias discursivas. Se trata de mirar cuál ha sido la historia que le ha otorgado o le ha restado legitimidad a la paz en Colombia, y cómo esta se ha alimentado $\mathrm{y}$ ha perpetuado siempre una crisis; para ello, se hace un especial enfoque en las campañas presidenciales entre el 2002 y el 2014, así como en la campaña para el plebiscito por la paz del 2016, desde el punto de vista de la narración, tanto visual como oral.

\section{Antecedentes}

La mayoría de los trabajos que se dedican en Colombia al análisis del discurso lo hacen desde una perspectiva cuantitativa (González, 2016) o cualitativa (Pardo, 2007). El enfoque cuantitativo presenta la ventaja de identificar claramente cuáles son los términos recurrentes $\mathrm{y}$, por ende, los más relevantes en los discursos de la clase dirigente colombiana. González, por ejemplo, en su riguroso estudio El poder de la palabra. Uribe, Santos, Chávez y las FARC (2016), pone en perspectiva los discursos de estos cuatro actores $\mathrm{y}$ ofrece un análisis interesante que destaca las características de cada uno gracias a la herramienta lexicométrica. Por otro lado, los métodos del análisis de contenido $(\mathrm{AC})$ y del análisis crítico del discurso (ACD) permiten indagar 
sobre las lógicas estructurales y discursivas que existen en los contenidos discursivos. Retomando los aportes tanto de González como de la escuela del análisis de contenido, propondremos un modelo mixto de análisis, que asocia la contabilidad de las palabras al estudio de los términos clave dentro de unos frames que les confieren sentido dentro del texto. Por otro lado, utilizaremos otras unidades de estudio, que son las historias dentro de los afiches electorales, más amplias que las palabras solas, y que corresponden también a unidades construidas destinadas a crear sentido (Greimas, 1970).

\section{Storytelling, política y narratividad}

Nuestra hipótesis establece que el tema de la paz en Colombia siempre se ha alimentado de un escenario de crisis o ha contribuido a alimentarlo. Para desarrollarla, resulta fundamental definir cuáles son las dos historias que el uribismo y el antiuribismo han difundido elección tras elección en los últimos quince años. En este trabajo, se retomará la definición planteada por Richard y González (2016), en la cual el uribismo se entiende como un movimiento que contempla la realidad histórica del país y que considera a la seguridad como el factor fundamental para solucionar otros problemas de índole social, económica y cultural. Según esta concepción, la única manera de ser un Estado seguro es a través de la eliminación, por la vía militar, de los grupos al margen de la ley. Por otro lado, los antiuribistas serán todas aquellas personas o grupos políticos que se oponen a esta visión: contemplan el desarrollo del país más allá de la seguridad y creen en la posibilidad de acabar con el conflicto armado por la vía de la negociación (Richard y González, 2016, p. 39).

Estas dos visiones -uribistas y antiuribistas - dominaron las contiendas electorales de los años 2002, 2006, 2010 y 2014; en este sentido, las campañas electorales fueron un teatro en donde se enfrentaron historias antagónicas en cuanto a cómo se debía alcanzar la paz en Colombia. Estas historias encajan en la disciplina del storytelling o "arte de contar historias" (Salmon, 2007). Ello estipula que una historia es, antes de todo, un discurso narrativo dirigido hacia el imaginario. Para que los que escuchan aprecien y recuerden la historia, es necesario que la narración se inscriba dentro de un marco histórico común, un elemento que reúna. Estas historias se inspiran en una memoria colectiva que las alimenta y, por esta razón, las historias que promocionan positivamente a los políticos son, muchas veces, las que se adaptan mejor a estos imaginarios.

Cada historia contada debe encajar dentro del marco de una cultura política propia y manejar las referencias históricas y culturales comunes para lograr llegar a toda la nación, dado que es "a través de la narración como damos significado y legitimidad a la realidad cultural" (Rincón, 2006, p. 91). Para Anderson (2006), "el camino a 
una identificación nacional ha sido y sigue pavimentado por narrativas monumentales en el proceso de una construcción de 'comunidades imaginadas' que se consolidan mediante las historias" (p. 17). Barthes (1957) agrega que "la historia es la llave maestra, la narración es una de las grandes categorías del conocimiento que nos permite entender y organizar el mundo" (p. $110)$. Por ende, resulta interesante analizar las campañas electorales como historias en las cuales se enfrentan héroes y villanos, unos actantes, como los define Greimas (1970), cuyo papel en la historia está definido gracias a la herramienta del esquema actancial en el cual un sujeto (el héroe) se encuentra en la búsqueda de un objeto (puede ser la paz); los personajes, eventos u objetos positivos que lo ayudan se llaman ayudantes (los electores, los aliados políticos) y los que lo retan son los oponentes (los otros políticos). La búsqueda empieza cuando el iniciador (destinador) lo indica para el beneficio del destinatario (esencialmente los colombianos) (Richard, 2014). En estas historias que fueron contadas a los colombianos a través de varios escenarios electorales, veremos que el espectro de la crisis siempre ocupa una posición importante.

\section{Metodología}

Para entender cuáles son las historias que se contaron en los distintos escenarios electorales, analizaremos varios elementos en los cuales están plasmadas estas historias, tales como los discursos y los afiches electorales. El enfoque que usaremos para este fin es el de la semiótica, entendiéndola como una herramienta epistemológica que aborda la interpretación y producción del sentido, o, según Peirce (1883), "el proceso de asociación de signos en la producción de significación interpretativa". Esa "ciencia que estudia los diferentes sistemas de signos que permiten la comunicación entre individuos, sus modos de producción, de funcionamiento y de recepción" (Real Academia Española, 2012) nos guiará para entender de qué manera los signos usados en diferentes soportes (como las palabras en discursos o los símbolos en afiches electorales) construyen sentido para quien los lee ${ }^{3}$.

Para este fin, la investigación propone, en un primer momento, un análisis semiótico de los soportes visuales de las campañas electorales presidenciales entre el 2002 y el 2014; es decir, una evaluación cualitativa del afiche de campaña considerado no desde su dimensión estética o como fenómeno

3 La utilización de ciertos colores, por ejemplo, permite transmitir ideas; así, el color blanco evoca las ideas de paz o de transparencia; el azul, la esperanza; el rojo, la agresividad, la vida o la sangre. Los objetos también son signos: el globo terrestre evoca la globalización, la humanidad o las relaciones internacionales; la paloma simboliza la paz; la balanza, la justicia, etcétera. 
emocional, sino como significación. En un segundo tiempo, se analizarán los discursos presidenciales pronunciados en alocuciones oficiales, cada uno frente a un escenario de crisis, un escenario internacional o nacional donde se evocan los lineamientos generales de la política de gobierno ${ }^{4}$. En este caso, los signos que se van a interpretar están conformados por las palabras que agruparemos en frames o encuadres. Como señala Van Dijk, el discurso, tomado en términos generales, es una manifestación tangible de las interacciones sociales; asimismo, el discurso político representa las interacciones entre los diversos grupos sociales con poder (Wodak, 2002). De esta manera, por medio del discurso político, se pueden observar los elementos comunicativos que se usan para establecer o mantener las relaciones de poder entre los diferentes grupos sociales. El objetivo del discurso político es el de convencer a un determinado grupo social (Van Dijk, 1997; Wodak, 2002). En consecuencia, las acciones desarrolladas a través de la interacción construida a partir del discurso se legitiman y dan lugar a una serie de medidas; en este caso, la política para luchar contra la crisis.
A través de prácticas discursivas, se puede dar o reforzar el significado de un hecho o de un texto, lo que resulta interesante en el caso de esta investigación. El acceso a los tipos de discurso que permiten ejercer algún tipo de influencia confiere un relativo poder a quien lo emite; el reforzamiento del discurso a través de prácticas discursivas da lugar a una serie de acciones para legitimar la política uribista de "lucha contra el terrorismo" o la política santista de diálogo con el enemigo.

Para terminar, se analizará el framing de la firma de los acuerdos de paz de La Habana entre el presidente Santos y el líder máximo de la guerrilla de las FARC-EP en setiembre del 2016. Se hará especial énfasis en la puesta en escena del evento y la utilización de ciertos frames destinados a motivar una lectura orientada de los hechos. Un frame debe ser entendido así:

Un cuadro de lectura que sirve para seleccionar y poner en evidencia ciertas características de la realidad y para minimizar otras con el fin de contar una historia coherente sobre los problemas, las causas, las implicaciones morales y las soluciones. (Entman, 1996)

4 Los discursos para el análisis fueron seleccionados por ser oficiales y tener relevancia en la comunicación de gobierno. Los uribistas son los siguientes: declaración del presidente tras el atentado en El Nogal (Bogotá), 8 de febrero del 2003 (escenario de crisis); discurso de posesión, 2002 y 2006; e intervención ante la 64 Asamblea General de Naciones Unidas, setiembre del 2002 (escenario internacional). Los discursos santistas son el de la firma de la paz, Cartagena, setiembre del 2016; el discurso de posesión de los años 2010 y 2014; el discurso al recibir el Premio Nobel de la Paz, 2016 (escenario internacional); el discurso después del rechazo a los acuerdos de paz en el plebiscito (escenario de crisis). 
En el caso de los acuerdos de paz, el framing escogido buscaba enviar el mensaje de que la firma de los acuerdos era la solución a la crisis que representaba el conflicto armado. Sin embargo, los símbolos fueron interpretados con otro framing por parte de los colombianos, que vieron en esta ceremonia la prueba de que el país ya se encontraba entre las manos de los castro-chavistas.

El estudio de los frames se basa en los trabajos de Street (2011), que especifica que si el hecho de cubrir la actualidad política en la televisión implica necesariamente recurrir al storytelling, entonces, la selección del tipo de la narración es fundamental en la representación de la política para los ciudadanos. Como lo resalta Tankard (2001), el estudio del framing en televisión es importante, dado que ofrece una posibilidad real y empírica de estudiar la ideología presente en las noticias de los medios $y$, aunque corresponde a un concepto sofisticado que va más allá de una presentación favorable o no de la noticia, reconoce que el frame tiene un efecto sutil, pero poderoso sobre la audiencia, lo que permite estudiar el impacto sobre las opiniones (Muñiz, 2015); en este caso, la victoria del No en el plebiscito por la paz después de la firma de los acuerdos de paz.

Para entender el uso adecuado del concepto de crisis en la comunicación gubernamental en Colombia, es necesario empezar por el principio de la historia: el nacimiento del uribismo.

\section{Resultados}

Campaña de los años 2002 y 2006: Uribe como hombre providencial. El héroe que todo el mundo esperaba o la crisis como argumento electoral

\section{El 2002, la llegada inesperada del héroe y el fin de la crisis}

El final de la presidencia de Andrés Pastrana en el año 2002 se cierra con el rotundo fracaso de los diálogos de paz en El Caguán. Este episodio marca el fortalecimiento de la guerrilla de las FARC-EP por una parte y el debilitamiento del Estado por otra (Echandía, 2006). Esta situación genera también un escenario de crisis gubernamental que va a ser aprovechado por un pequeño candidato a la presidencia, exgobernador de la región de Antioquia y disidente del Partido Liberal, Álvaro Uribe, quien se lanza con el eslogan de "Mano firme, corazón gran-

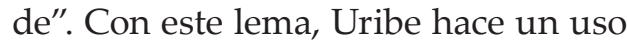
acertado del storytelling, al contar una historia basada en una estructura narrativa que sirve para la elaboración de todos los cuentos populares que habitan los imaginarios colectivos (Richard, 2008). Su historia sigue la trama narrativa que se muestra en la figura 1.

Uribe hace coincidir el principio de su campaña después de la etapa de la crisis asimilada al fracaso de las negociaciones de paz y el fortalecimiento del enemigo. La historia cuenta la aparición del héroe, el salvador que 
Figura 1. Momento de la campaña uribista del 2002 en la trama narrativa

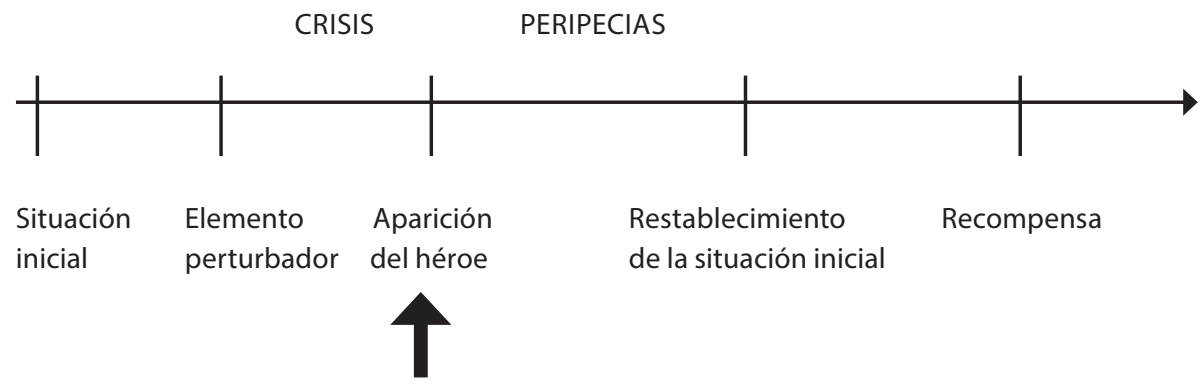

Fuente: Larivaille (1974). Elaboración propia

viene para resolver la crisis y restablecer la situación. Uribe es el hombre providencial, el líder que todo el país esperaba, el único capaz de actuar. La narrativa escogida por el candidato es, entonces, hábil para lograr el objetivo, pues el público sabe que, en esta historia, no existe espacio para ningún otro pretendiente. Su elección aparece entonces como una necesidad para que el país pueda salir de la crisis (Richard, 2008). En su propaganda electoral, Uribe hace uso de símbolos y de una retórica nueva, que rompen con lo convencional y que lo asimilan a un hombre mesiánico, trabajador y comprometido que defiende la seguridad, el futuro y el patriotismo. Tanto el personaje como la narrativa se alimentan de la situación de crisis que implica el fracaso de los diálogos de paz para cobrar relevancia y propulsar al candidato a la presidencia desde la primera vuelta de las elecciones. El esquema actancial de Greimas (1970) permite evidenciar los diferentes actantes presentes en una historia (véase la figura 2).

\section{Figura 2. Esquema actancial según Greimas}

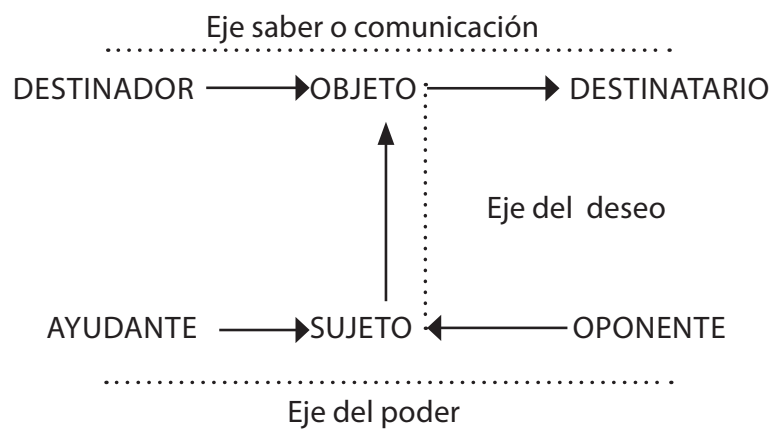

Fuente: Greimas (1970) 
Para entender adecuadamente este esquema, no se puede olvidar que los roles actanciales (es decir, los actantes) no deben ser asimilados a unos actores. Los actantes representan posiciones dentro de una estructura, se definen por sus relaciones y desempeñan un papel en la historia. Además, se ubican sobre tres ejes que los relacionan de manera significativa: el sujeto y el objeto (el héroe y el objetivo) están situados sobre el eje del deseo (el héroe desea conseguir el objeto mediante su búsqueda). El iniciador (o destinador, también conocido como fuente enunciativa) y el destinatario se encuentran sobre el eje de la comunicación (el iniciador motiva la búsqueda del objeto por parte del héroe para el destinatario). El iniciador representa, en la mayoría de los casos, los valores en nombre de los cuales actúa el héroe. El personaje actúa solamente cuando el iniciador lo pone a actuar $\mathrm{y}$, al final del relato, es el mismo iniciador quien "sanciona" el éxito o el fracaso de la búsqueda del héroe, según si este logró conseguir el objeto de su búsqueda o no. Por último, los ayudantes y los oponentes están sobre el eje del poder (suman o restan poder al héroe en su búsqueda). Aplicándolo al guion uribista, el esquema se presenta en la figura 3. Y la misma narrativa se vuelve a encontrar en el afiche de campaña en la figura 4.

Figura 3. Esquema actancial del guion uribista

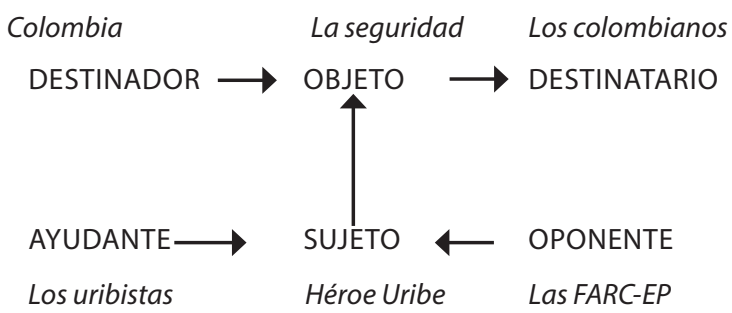

Elaboración propia

Figura 4. Afiche electoral de Uribe, elecciones presidenciales del 2002

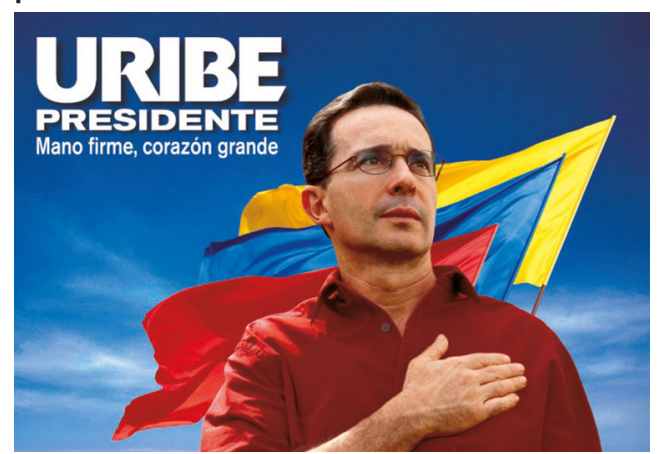

Fuente: Uribe Vélez (2002) 
El personaje (sujeto/héroe) puesto en escena es el de un hombre mesiánico, cuya mirada al horizonte traduce la esperanza y la confianza en el futuro y en el proyecto político que se contempla. La mano en el corazón expresa el patriotismo del candidato, pero también ilustra el lema de campaña con la representación de una mano firme y un corazón grande. La camiseta roja es la de Carlos Galán, otro gran héroe popular, asesinado en 1989, del cual el candidato se reclama seguidor con el uso de este símbolo. Las banderas que están atrás, cuyos colores recuerdan la bandera nacional de Colombia (fuente enunciativa), proyectan a Uribe como un hombre que encarna la nación, candidato de todos los colombianos (destinatarios) que se reconocen en este símbolo patrio; pero es también la bandera roja de los liberales, la azul de los conservadores y la amarilla de los independientes. El cielo azul, símbolo de felicidad, muestra un futuro abierto y sin nubes a la vista. Por fin, el ángulo con el que se sacó la foto presenta al candidato con una ligera posición de superioridad con respecto al observador, lo que manifiesta, por una parte, su dimensión mesiánica y, por otra, la relación de autoridad, pero también de cercanía que establece con el pueblo.

Durante su primer mandato (20022006), el héroe realiza un ciclo de peripecias, restableciendo buenos indicadores en el campo de la seguridad. Durante cuatro años, la historia sigue su curso y es contada hasta el momento final, el de la recompensa que siempre cierra la narración de las historias populares y que se materializa, en este caso, en la figura de la reelección en el 2006.

\section{El 2006, el héroe plebiscitado por el pueblo}

A principios del año 2006, la crisis parece terminada, como lo prometió el héroe, quien se va a dedicar a buscar su recompensa. Uribe finaliza su primer mandato con unos índices de popularidad muy altos: según encuestas realizadas por la firma Gallup, el 55,7 \% de los colombianos tiene una imagen positiva del mandatario cuando lanza su campaña de reelección (Richard y González, 2016). Esta vez, la fuente enunciativa son los colombianos mismos: con el lema "Adelante, presidente", reclaman el retorno del héroe, mientras que el candidato apoya la continuidad

Figura 5. Momento de la campaña uribista del 2006 en la trama narrativa

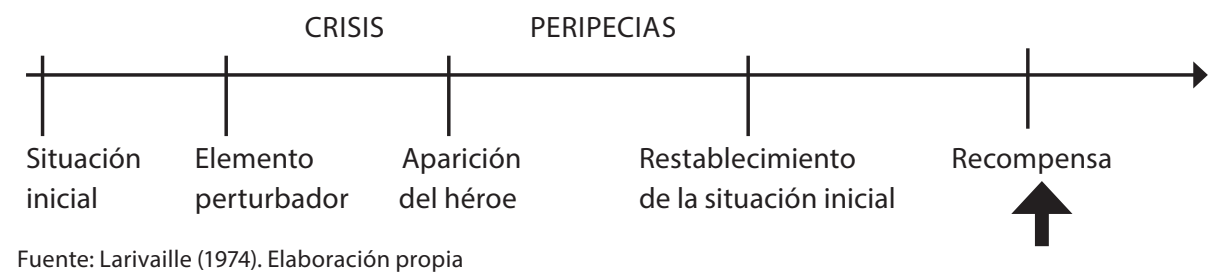


Figura 6. Afiche electoral de Uribe, elecciones presidenciales del 2006

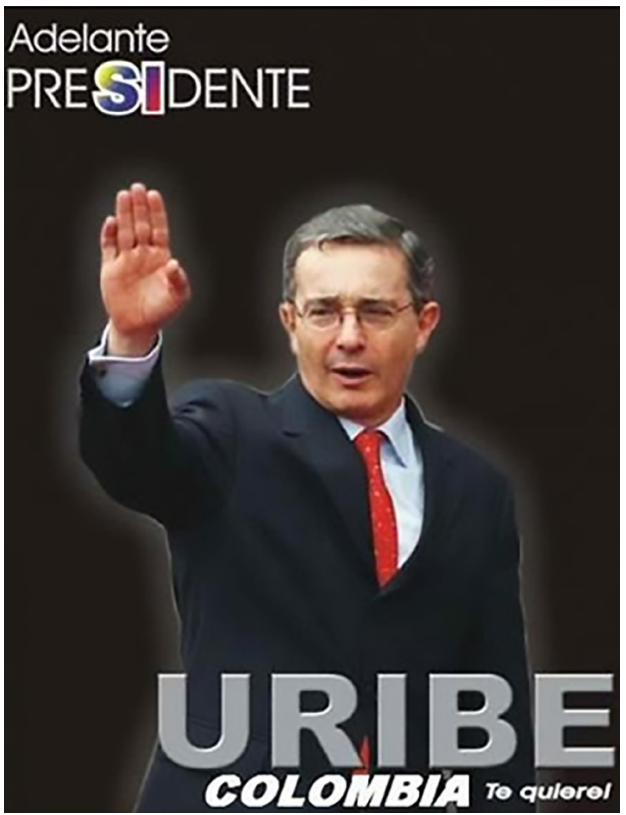

Fuente: Uribe Vélez (2006)

de su política de "seguridad democrática". La historia se ubica en el momento indicado en la figura 5.

Retomando el estudio de Richard y González (2016), podemos ver que en el afiche el lema aparece con la sílaba si de presidente resaltada con los colores de la bandera. El héroe Uribe está de frente, saludando a un público que es también el observador (destinatario). El hombre es ahora un estadista y se presenta como tal, con los atributos tradicionales de la función presidencial que son el traje y la corbata. Un leve brillo blanco lo rodea y le confiere un aura especial, como la de un santo. El ángulo en contrapicado de la foto es el mismo que se viene trabajando desde el 2002 y ubica al candidato en una posición de superioridad. Varios elementos de la campaña anterior son retomados: el apellido Uribe aparece en letra grande y ocupa casi todo el espacio, no hay ninguna sigla de un partido político, y la bandera, un símbolo ya utilizado anteriormente, aparece en el si, haciendo alusión a Colombia presente en la frase: "Colombia te quiere". El valor dominante en la imagen es el del querer, mientras que, en el 2002, era el del poder. Se trata aquí de una declaración de amor del pueblo colombiano hacia su líder: la fuente enunciativa no corresponde al candidato, sino al pueblo soberano que impulsa la candidatura de Uribe y justifica un segundo mandato, hasta ahora prohibido por ley a cualquier otro presidente (Richard y González, 2016).

Por otra parte, el análisis del vocabulario que usa el presidente entre el 2002 y el 2010 en algunos de sus discursos oficiales participa en la producción de un mensaje verbal similar al visual y sigue alimentando la misma narrativa. El campo lexical (o frame) del patriotismo es el que domina la retórica presidencial uribista: las palabras Colombia, pueblo, nación, comunidad y país son repetidas entre $47 \mathrm{y}$ 22 veces en 5 discursos. Esas reiteraciones demuestran la importancia del proyecto patriótico del presidente que encarna la nación. El frame de la legalidad llega, de hecho, en segunda posición con las palabras Estado, 
gobierno, congreso, democracia, política y ley, con un máximo de 50 repeticiones y un mínimo de 22. La palabra presidente, por su parte, aparece 10 veces en 5 discursos. El tercer frame presente es el de las metas, donde dominan los términos como paz, inversión, justicia, equidad, empleo y salud (repetidas entre 30 y 12 veces). El frame de la confrontación es igualmente importante, como es de imaginar, dado que Uribe se hizo elegir dos veces sobre el argumento de la seguridad. Tiene un total de 186 repeticiones y las palabras más usadas son seguridad, terrorismo, seguridad democrática, fuerza, violencia, lucha, terroristas, autoridad, droga, guerrilla y dolor (entre 32 y 10 repeticiones). Cabe resaltar, por fin, que la palabra crisis está casi ausente de los discursos uribistas, incluso cuando el presidente se pronuncia después del atentado al Club de El Nogal en pleno centro de Bogotá por parte de las FARC-EP en el año 2003. La palabra solo aparece 3 veces en los 5 discursos y demuestra que la estrategia discursiva uribista consiste en desaparecer este concepto de los imaginarios durante su presidencia.

Cuando el presidente llega al fin de su segundo mandato en el 2010, se despide con unos excelentes índices de popularidad del $80 \%$ ("Presidente Álvaro Uribe termina su gestión con 80 \% de aprobación", 2010) y sus seguidores son muchos, tanto en la ciudadanía como en la clase política. Con el fin de beneficiarse del capital político del presidente saliente, varios de los candidatos retoman la narrativa uribista para posicionarse como herederos del popular héroe.

\section{Campaña del 2010 y 2014: Santos, de hijo pródigo a traicionero}

\section{Del 2010 al 2012: Santos, de heredero de Uribe a traicionero máximo}

En el 2010, empieza en Colombia una era política nueva, la del posuribismo. El expresidente marca un hito en la historia nacional y crea un antes y un después, con el cual los nuevos candidatos se ven obligados a competir. El tema del conflicto armado y, por ende, de la crisis sigue dominando la agenda de las campañas con una clara dicotomía entre vía armada o vía negociada para su resolución. Juan Manuel Santos, el hijo legítimo del uribismo, se apodera del relato del expresidente para encarnar la continuidad (Richard y González, 2016). Santos aprovecha que la narración había llegado al fin de su ciclo (después de la recompensa) para señalar la amenaza que puede representar abandonar la historia, lo que significaría la reaparición de la crisis. Sus afiches de campaña materializan este temor, con un mensaje enmarcado por una campaña de angustia, ligada a la idea del retorno de la inseguridad bajo todas sus formas. El lema "Para seguir avanzando" adopta esta lógica, suscitando esencialmente el miedo al cambio (Richard y González, 2016).

La historia que se cuenta es, por ende, la del posible retorno de la crisis 
Figura 7. Afiche electoral de Santos, elecciones presidenciales del 2010

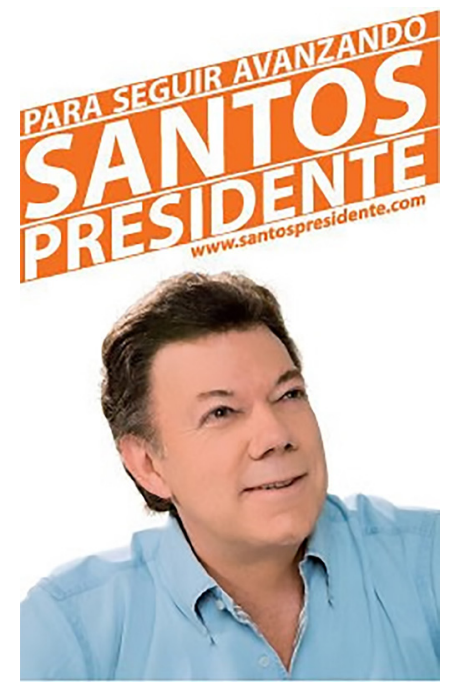

Fuente: Afiche de la campaña "Santos Presidente 2010" (2010)

si se abandona la política de seguridad democrática. Sin embargo, esta idea basada en el miedo, cultivada por Uribe y plasmada en el eslogan, no se traduce en ningún elemento gráfico, ni tampoco en el uso de una modalidad, y estos errores de comunicación estratégica casi les cuesta la presidencia a los uribistas (Richard y González, 2016). Santos triunfa finalmente en las urnas, pero la historia marca un giro drástico en el 2012 cuando anuncia la apertura en La Habana (Cuba) de los diálogos de paz entre una delegación de su gobierno y la guerrilla de las FARC-EP. El presidente pierde entonces su estatuto de "heredero legítimo de Uribe"; esta maniobra de acercamiento con el enemigo fue asimilada por los uribistas como una traición inaceptable a su causa de la seguridad democrática. Santos se vuelve un aliado de los terroristas, pasando de ayudante a oponente del héroe, según la clasificación de los actantes de Greimas (1970).

Por su parte, Santos inaugura una nueva historia en la cual él es el héroe central, mientras Uribe y sus seguidores son los "enemigos de la paz" (oponentes) que no dejan que Colombia pueda acabar con la etapa de crisis dentro de la cual está inmersa desde hace más de cinco décadas por el conflicto armado. Uribe, exdestinador, es ahora el jefe de la oposición, el antihéroe contra el cual tiene que luchar el héroe Santos para acabar con el ciclo de violencia uribista y así llegar a un "nuevo amanecer",

Figura 8. El esquema actancial del guion santista

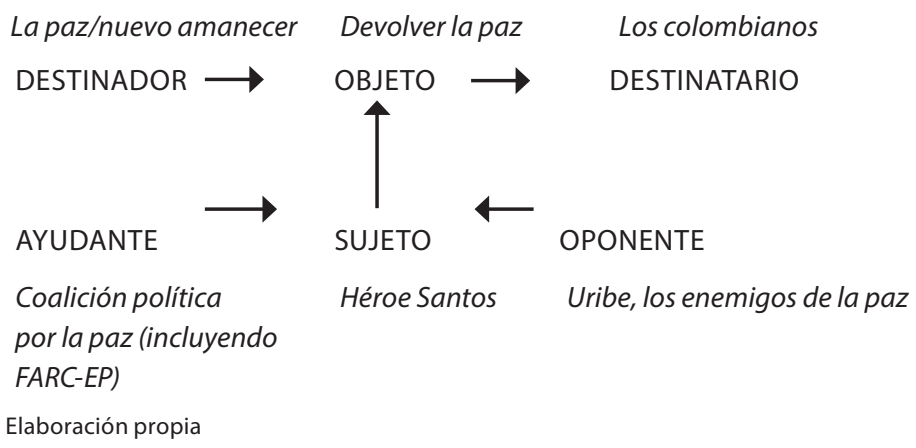


símbolo de paz y de prosperidad. El esquema actancial adopta, por ende, la forma de la figura 8.

Esta narrativa es la que se vuelve a encontrar en la campaña santista de reelección en el año 2014.

\section{El 2014: el presidente de la paz}

Mientras la ruptura parece resumida entre uribismo y santismo para la nueva campaña presidencial, resulta interesante anotar que tanto Uribe como Santos se hacen elegir cada uno dos veces sobre el argumento de la crisis. Sus campañas se alimentan de este elemento $y$, sin crisis, sus personajes de héroes no tendrían razón de ser. Uribe es el hombre providencial y el líder carismático que se erige como protector del pueblo colombiano y como remedio a la crisis; en cambio, Santos es, la primera vez, el garante uribista contra el retorno de la crisis y, la segunda vez, "el presidente de la paz", quien dialoga con la guerrilla cuando la crisis se ha vuelto sinónimo de conflicto armado alimentado por la política uribista. En este sentido, la crisis ya no justifica la política de lucha armada contra la guerrilla, sino que se vuelve la causa de las negociaciones. En otras palabras, uribismo y santismo encuentran siempre en la crisis un elemento oportuno de justificación de su actuar político.

De hecho, el análisis comparativo de los discursos de Santos y Uribe demuestra que ambos presidentes - que, al parecer, son totalmente opuestosmovilizan los mismos frames, aunque con un peso diferente: mientras Uribe hace mucho uso del frame del patriotismo, de la legalidad, de las metas y de la confrontación, se enfoca menos en los del trabajo colectivo, del Estado en acción y se refiere rara vez al encuadre de la esperanza (con solo dos términos: confianza y oportunidades).

En el caso de Santos, el frame de la confrontación llega en quinta posición, detrás del de las metas, que es el más presente con 384 repeticiones. El término paz es repetido más de 100 veces, seguido por mundo, acuerdo, justicia, proceso, desarrollo, seguridad, fin, equidad, prosperidad, educación, internacional, países, libertad, oportunidad y salud (entre 40 y 10 repeticiones). Sigue el frame del trabajo colectivo (283 repeticiones), el del patriotismo (262 repeticiones) y el de la esperanza, con 152 repeticiones de las palabras posible, vida, hijos, mejor/ mejores, niños, podemos, futuro, jóvenes, amanecer, corazón y final. La utilización recurrente de estas palabras nos indican que la narrativa santista sigue siendo la misma con la que se inició los diálogos de paz; es decir que el país está empezando hasta ahora una historia nueva que lo llevará hacia un mejor futuro de la mano de su líder de la paz. Los frames que menos aparecen en el discurso santista son los del Estado en acción (114 menciones) y legalidad (112 menciones). La tabla 1 
Tabla 1. Presencia de los frames en los discursos presidenciales

\begin{tabular}{|c|c|c|c|c|c|}
\hline $\begin{array}{c}\text { Uribe } \\
\text { (15 } 573 \\
\text { palabras) }\end{array}$ & $\begin{array}{c}\text { Número } \\
\text { de } \\
\text { repeticiones }\end{array}$ & $\begin{array}{c}\text { Palabras } \\
\text { clave }\end{array}$ & $\begin{array}{c}\text { Santos } \\
\text { (14 378 } \\
\text { palabras) }\end{array}$ & $\begin{array}{c}\text { Número } \\
\text { de } \\
\text { repeticiones }\end{array}$ & $\begin{array}{c}\text { Palabras } \\
\text { clave }\end{array}$ \\
\hline 1. Patriotismo & 219 & $\begin{array}{l}\text { Colombia, } \\
\text { pueblo, } \\
\text { nación }\end{array}$ & 1. Metas & 384 & $\begin{array}{l}\text { paz, } \\
\text { acuerdo, } \\
\text { justicia }\end{array}$ \\
\hline 2. Legalidad & 217 & $\begin{array}{l}\text { Estado, } \\
\text { gobierno, } \\
\text { Congreso }\end{array}$ & $\begin{array}{l}\text { 2. Trabajo } \\
\text { colectivo }\end{array}$ & 283 & $\begin{array}{l}\text { todos, } \\
\text { nuestra, } \\
\text { nuestro }\end{array}$ \\
\hline 3. Metas & 207 & paz, inversión & 3. Patriotismo & 262 & $\begin{array}{l}\text { Colombia, } \\
\text { país }\end{array}$ \\
\hline 4. Confrontación & 186 & $\begin{array}{l}\text { seguridad, } \\
\text { terrorismo, } \\
\text { seguridad } \\
\text { democrática }\end{array}$ & 4. Esperanza & 152 & $\begin{array}{l}\text { mejor, } \\
\text { posible }\end{array}$ \\
\hline $\begin{array}{l}\text { 5. Trabajo } \\
\text { colectivo }\end{array}$ & 150 & $\begin{array}{l}\text { nuestra, } \\
\text { nuestro }\end{array}$ & 5. Confrontación & 132 & guerra \\
\hline $\begin{array}{l}\text { 6. Estado } \\
\text { en acción }\end{array}$ & 93 & crecimiento & $\begin{array}{l}\text { 6. Estado } \\
\text { en acción }\end{array}$ & 114 & $\begin{array}{l}\text { vamos, } \\
\text { quiero }\end{array}$ \\
\hline 7. Esperanza & 48 & confianza & 7. Legalidad & 112 & gobierno \\
\hline
\end{tabular}

Elaboración propia

resume los hallazgos del análisis comparativo de los discursos de gobierno uribistas y santistas.

Si bien la palabra crisis casi no aparece en los discursos de los presidentes, del 2002 al 2014 los términos guerra y paz son recurrentes y siempre son una alusión a la crisis que se impone como temática dominante de los discursos electorales e institucionales de los gobiernos de turno. Uribe se sabe aprovechar de la crisis y la convierte en un elemento central de su narrativa de campaña y de gobierno; mientras que
Santos también se beneficia de la crisis, retomando la historia donde la dejó su líder, pero decide romper brutalmente con la lógica narrativa uribista cuando instala los diálogos de paz. La crisis es ahora el conflicto armado, el héroe se vuelve villano, cada actante del cuadro semiótico está reubicado y hasta la moraleja de la historia se redefine. Sin embargo, los uribistas siguen difundiendo en los imaginarios colectivos su propia narrativa, según la cual Santos es el traidor que se ha convertido a la causa de los enemigos del país 
y que estos, gracias a los acuerdos de paz que fueron firmados a espaldas de los colombianos, terminarán impunes de los delitos cometidos. Esta historia será la que se impondrá en el plebiscito para la paz.

\section{Plebiscito 2016: cuando el framing cuenta otra historia}

Una vez cerrados con éxito los diálogos de paz en La Habana, Santos protagonizó, con su delegación y la de las FARC-EP, el evento de la firma oficial del documento en la ciudad de Cartagena. La ceremonia tenía como fin convencer de manera simbólica a los televidentes de la gran oportunidad que representaba esta firma para el país, gracias a una puesta en escena muy solemne del evento, y generar entusiasmo por el Sí en el plebiscito.

Sin embargo, el resultado fue lo opuesto: la gran similitud entre los discursos del presidente y del comandante de las FARC-EP, Rodrigo Londoño alias Timochenko, generaron confusión y miedo, mas no seguridad, y la fastuosa puesta en escena del evento fomentó una sensación de triunfalismo por parte del gobierno y de las FARC-EP. Los colombianos sintieron que Santos y su nuevo aliado estaban escribiendo una nueva historia con la cual no estaban del todo de acuerdo: los antiguos villanos se volvían héroes, y Santos abandonaba a sus antiguos ayudantes, el pueblo colombiano, por los antiguos terroristas. Los que no se reconocían en esta historia eran ahora los "enemigos de la paz", los que se pronunciaron algunos días después, haciendo ganar el No en el plebiscito por la paz y generando una nueva crisis para el gobierno de Santos.

\section{La deconstrucción de la narrativa} santista

La agrupación de las palabras más mencionadas por Santos y Timochenko en sus discursos en distintos frames evidencia unas significantes semejanzas que desconcertaron al electorado: el antiguo oponente del gobierno pareció hablar de repente con la misma voz que el presidente, el sujeto, hasta transformarse en un ayudante de igual importancia y legitimidad. De los 8 frames del jefe de la guerrilla, 7 coinciden con los utilizados por el presidente, lo que asciende a un $88 \%$ el nivel de semejanza entre los dos discursos.

En la utilización de los términos se reitera la similitud. La palabra paz fue la más mencionada en las dos alocuciones: 24 veces para Santos y 34 para Timochenko. Sin embargo, resulta lógico que este término sea central en ambos discursos que ponen un punto final al conflicto armado, incluso si en el discurso de Santos se empleó aún más con una diferencia de casi 1 punto porcentual.

Por otra parte, los dos discursos recalcaron la trascendencia del evento 
Tabla 2. Presencia de los frames en los discursos de la firma de los acuerdos de paz

\begin{tabular}{|c|c|c|c|c|c|}
\hline $\begin{array}{c}\text { Timochenko } \\
\text { (3282 } \\
\text { palabras) }\end{array}$ & $\begin{array}{l}\text { Número } \\
\text { de } \\
\text { repeticiones }\end{array}$ & $\begin{array}{c}\text { Palabras } \\
\text { clave }\end{array}$ & $\begin{array}{c}\text { Santos } \\
(2131 \\
\text { palabras) }\end{array}$ & $\begin{array}{l}\text { Número } \\
\text { de } \\
\text { repeticiones }\end{array}$ & $\begin{array}{c}\text { Palabras } \\
\text { clave }\end{array}$ \\
\hline 1. Comunidad & 72 & $\begin{array}{l}\text { todos, } \\
\text { nuestros, } \\
\text { nuestra, } \\
\text { nuestro }\end{array}$ & 1. Comunidad & 52 & $\begin{array}{l}\text { todos, } \\
\text { nuestro, } \\
\text { nuestra, } \\
\text { gracias a }\end{array}$ \\
\hline 2. Patriotismo & 61 & $\begin{array}{l}\text { Colombia, } \\
\text { pueblo, } \\
\text { patria, país, } \\
\text { colombianos, } \\
\text { colombianas }\end{array}$ & $\begin{array}{l}\text { 2. Paz/ } \\
\text { negociación }\end{array}$ & 46 & paz, acuerdo \\
\hline $\begin{array}{l}\text { 3. Paz/ } \\
\text { negociación }\end{array}$ & 59 & $\begin{array}{l}\text { paz, acuerdo, } \\
\text { firma }\end{array}$ & $\begin{array}{l}\text { 3. Importancia } \\
\text { simbólica del } \\
\text { evento }\end{array}$ & 27 & $\begin{array}{l}\text { hoy, final, } \\
\text { mundo }\end{array}$ \\
\hline 4. Legalidad & 56 & $\begin{array}{l}\text { FARC-EP, } \\
\text { política, } \\
\text { político, } \\
\text { presidente, } \\
\text { comandante, } \\
\text { democracia }\end{array}$ & 4. Conflicto & 25 & $\begin{array}{l}\text { guerra, } \\
\text { conflicto, } \\
\text { violencia }\end{array}$ \\
\hline $\begin{array}{l}\text { 5. Importancia } \\
\text { simbólica del } \\
\text { evento }\end{array}$ & 40 & $\begin{array}{l}\text { final, fin, } \\
\text { hoy, historia, } \\
\text { mundo, ahora }\end{array}$ & 5. Patriotismo & 25 & $\begin{array}{l}\text { Colombia, } \\
\text { colombianos }\end{array}$ \\
\hline 6. Conflicto & 33 & $\begin{array}{l}\text { guerra, } \\
\text { conflicto, } \\
\text { armas }\end{array}$ & 6. Legalidad & 22 & $\begin{array}{l}\text { Estado, hacer, } \\
\text { gobierno, } \\
\text { presidente, } \\
\text { Santos }\end{array}$ \\
\hline 7. Esperanza & 32 & $\begin{array}{l}\text { reconciliación, } \\
\text { adelante, } \\
\text { esperanza, } \\
\text { futuro, niños, } \\
\text { hijos }\end{array}$ & 7. Víctimas & 13 & $\begin{array}{l}\text { vidas, } \\
\text { víctimas, } \\
\text { campesinos }\end{array}$ \\
\hline 8. Víctimas & 13 & $\begin{array}{l}\text { víctimas, } \\
\text { mujeres, niñas }\end{array}$ & NA & NA & NA \\
\hline
\end{tabular}

Elaboración propia 
de Cartagena como el comienzo de una etapa nueva y la culminación de una vieja, situación que contradecía la frase santista que se conoció como la regla para llevar a buen puerto los acuerdos de paz: "Nada está acordado, hasta que todo esté acordado" ("Miembros de las FARC, bienvenidos a la democracia", 2016). Bajo esta regla, ningún punto negociado estaba garantizado mientras la totalidad del documento no fuera redactado y aprobado por los colombianos. En esta ceremonia, todo se dio por terminado mientras faltaba la decisión de la sociedad. Este error de comunicación estratégica fue explotado por la oposición que argumentó que el presidente y su nuevo aliado, el jefe de la guerrilla, pasaban por alto la decisión soberana del pueblo.

El frame de la importancia simbólica del evento fue significativo en ambos discursos. En el de Santos, representó el $9 \%$ del discurso con 27 repeticiones y cuya palabra más destacada, hoy, fue repetida en 16 oportunidades. También la palabra final fue muy relevante, con 5 repeticiones, la cual enfatiza el fin de la etapa de conflicto. Lo mismo sucedió con Timochenko, quien mencionó la palabra final en 12 oportunidades y palabras como ahora y hoy, que recalcan la importancia del evento para la historia del país, 4 y 8 veces respectivamente. En cuanto a este frame, fue el quinto más mencionado con un total de 46 repeticiones de las distintas palabras que conforman la cadena cohesiva y un promedio de repeticiones del 6,7 \%.
Por último, y confirmando lo dicho anteriormente, los dos oradores no mencionaron en todo su discurso las palabras plebiscito ni elecciones, lo que generó un ambiente de triunfalismo y confianza excesiva por parte del gobierno, como si ya hubiese logrado su objetivo político.

Para finalizar, resulta interesante resaltar algunas diferencias entre las dos alocuciones. En primer lugar, Timochenko utilizó un léxico específico que contrasta con el del presidente: palabras como lucha, mencionada por el jefe guerrillero en 5 oportunidades, no fue enunciada por parte de Santos, lo que evidencia una diferencia ideológica entre los dos oradores y un nuevo discurso que se irá posicionando en el ámbito político colombiano. De igual manera, la forma como el comandante de la guerrilla abarcó en repetidas ocasiones el encuadre del patriotismo, utilizando 61 palabras relacionadas - mientras que para Santos este campo no fue tan significante (solo utilizó 25 palabras)-, muestra la relación más estrecha que él intenta construir con el pueblo, posicionándose como un personaje cercano a la gente con un discurso político patriótico (como el expresidente Uribe).

En fin, en el evento sorprendió la sensación de igualdad provocada por las alocuciones entre el héroe y su nuevo ayudante, es decir, el presidente de la República y el líder de la rebelión, así como las posiciones de triunfalismo de ambos. Esta posición también se pudo evidenciar en la puesta en escena 
de la ceremonia de firma de la paz, lo que permitió a la oposición aprovechar el malestar generado y proponer una nueva historia sinónima de crisis y desgobierno en el país.

\section{La construcción de una nueva crisis como consecuencia de la puesta en escena de la firma del acuerdo final en Cartagena}

La excesiva importancia que se le dio al evento se vio reflejada en varios elementos simbólicos: el número de invitados, que alcanzó la cifra de 2500, entre ellos 15 jefes de Estado y 27 cancilleres, y personalidades de gran importancia a nivel internacional ${ }^{5}$; y el costo total del evento, que se estimó entre los 1000 y 1500 millones de pesos ("Miembros de las FARC, bienvenidos a la democracia", 2016).

La magnitud del evento contrasta con la ceremonia de "bajo perfil" del segundo, en el que se realizó la firma de la paz en el Teatro Colón en Bogotá, después de haber triunfado el No en el plebiscito, y después de proceder a los ajustes solicitados; a este acontecimiento solo asistieron 750 invitados nacionales, sin la presencia de personalidades internacionales ("La firma de la paz", 2016). Esta segunda ceremonia
Figura 9. Llaves de la puerta hacia la paz

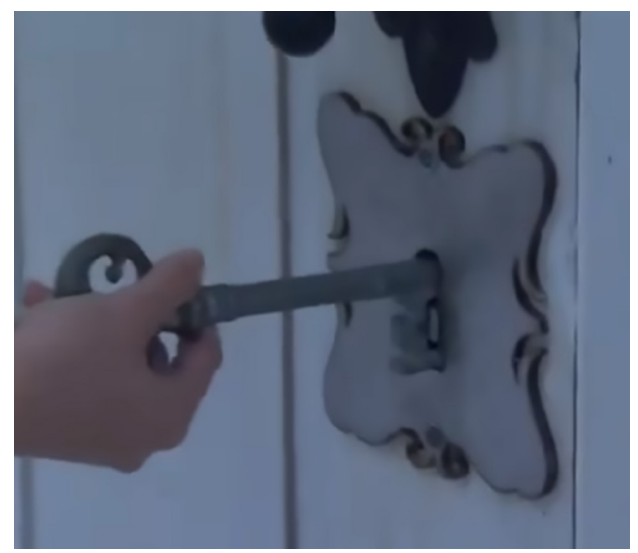

Fuente: Actualidad Colombia (2016)

tuvo lugar en un recinto cerrado con un número de invitados muy limitados, la mayoría congresistas colombianos. El evento en Cartagena duró aproximadamente una hora y media, mientras que el del Teatro Colón no demoró más de 48 minutos. La ceremonia de Cartagena empezó con un acto de alto impacto simbólico y emocional, que correspondió a la apertura por el presidente Santos de una puerta grande que llevaba hacia el escenario en donde los esperaba el público (véase la figura 9).

Sin embargo, el hecho de abrir la puerta para que tanto las FARC-EP como el gobierno ingresaran a la tarima

5 Ban Ki-moon (secretario general de las Naciones Unidas); el rey emérito de España, don Juan Carlos; Jim Yong Kim (director del Banco Mundial); Christine Lagarde (directora del Fondo Monetario Internacional); Luis Alberto Moreno (director del Banco Iberoamericano de Desarrollo); y Luis Almagro (secretario general de la OEA) (“Miembros de las FARC, bienvenidos a la democracia", 2016). 
principal volvió a generar una posición simbólica de igualdad entre los protagonistas, donde se pasaba del encierro hacia la libertad. El encierro de los guerrilleros era precisamente lo que pedía la oposición al gobierno, acusándolo de dejar libres e impunes a unos asesinos, invitándolos incluso a entrar en política con la misma facilidad con que subían a la tarima y dándoles la bienvenida como nuevos actores políticos.

Por otro lado, la exaltación de la izquierda se demostró en reiteradas ocasiones a lo largo del evento. Los primeros en cruzar la puerta, después del presidente Santos y Ban Ki-moon, fueron (por orden de llegada): Raúl Castro, presidente de Cuba; Timochenko, jefe de la guerrilla de las FARC-EP; Nicolás Maduro, presidente de Venezuela; y Rafael
Correa, presidente de Ecuador; todos de posturas izquierdistas. Minutos después, Timochenko, al aproximarse a su puesto final, enfrente de todo el público, alzó el puño como señal de triunfalismo y exaltación.

Desde otro ángulo, la firma de los acuerdos de paz con un balígrafo (bolígrafo fabricado con balas de fusil) fue un hecho importante. En el balígrafo está escrito: "Las balas escribieron nuestro pasado y la educación nuestro futuro" ("Conozca la historia del bolígrafo con el que se firmó la paz", 2016). Esta frase y el sentido simbólico del bolígrafo hacen referencia a un nuevo comienzo, donde se interpreta nuevamente el fin de un ciclo de violencia y el comienzo de otro. De igual forma, la firma representa la llegada de las FARC-EP al poder, no en definitiva, pero sí desde

Figura 10. Apretón de manos entre el presidente Santos y Timochenko

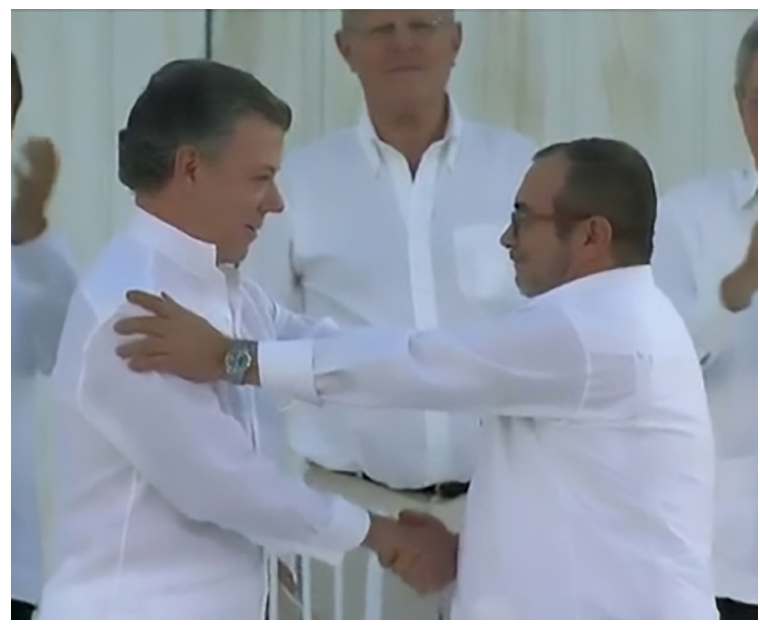

Fuente: Actualidad Colombia (2016) 


\section{Figura 11. Entrega de Santos a Timochenko de la paloma de la paz}

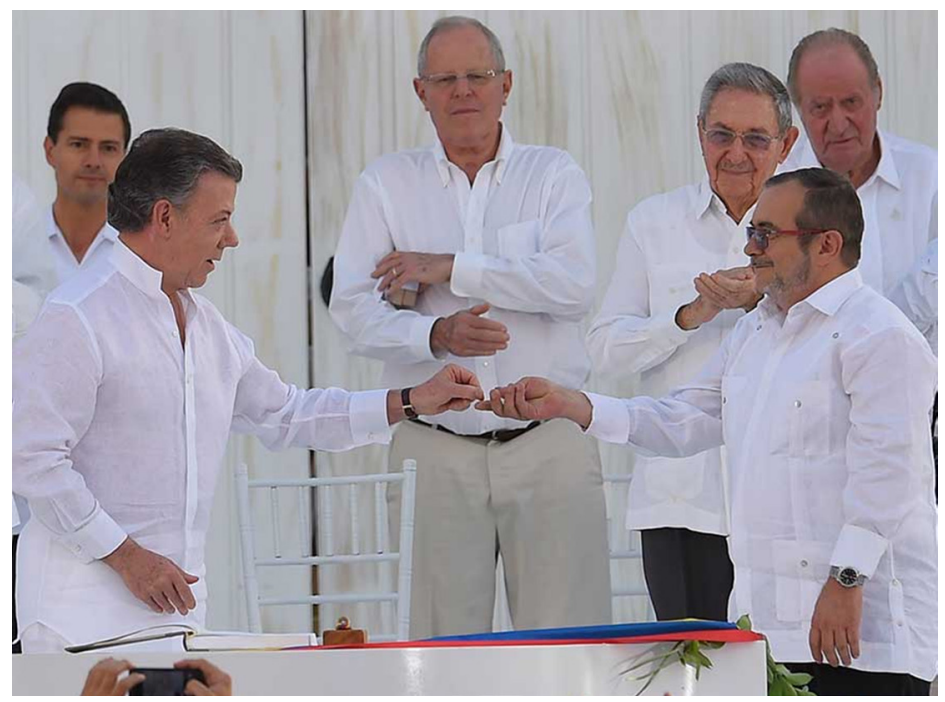

Fuente: Actualidad Colombia (2016)

una dimensión simbólica. La guerrilla, con la firma, aceptaba lo que estaba escrito en los acuerdos: entre muchos puntos, hacer política. De hecho, durante la ceremonia, Timochenko abandona su alias guerillero para volverse Rodrigo Londoño; es decir, acaba con su traje de guerrillero y se viste de político. La presentadora del evento se refiere a él incluso como "señor Rodrigo Londoño". Por fin, el apretón final de manos entre Santos y Londoño sella el pacto entre el héroe Santos que acaba de conseguir su objeto con sus antiguos oponentes.

Un último hecho sustancial fue el regalo de Santos al comandante de las FARC-EP: una paloma de la paz. Este obsequio pone en evidencia, nuevamente, la relación anfitrión-invitado, donde Londoño fue el centro del evento y la izquierda, la ideología triunfante. Asimismo, el tiempo dedicado a los discursos de Santos y Timochenko puso de manifiesto una clara desigualdad: el exjefe guerrillero obtuvo el mayor protagonismo por hablar primero, con una alocución de 30 minutos; contra 22 minutos para Juan Manuel Santos. Finalmente, el discurso del presidente obtuvo 15 rondas de aplausos, mientras que el del excomandante de las FARC-EP contabilizó 28 rondas (13 más que el presidente) por parte de los espectadores entusiasmados.

Los colombianos que siguieron esta transmisión en vivo vieron en la figura de Rodrigo Londoño al gran ganador del evento. Fue precisamente lo que denunció el jefe de la oposición, 
Álvaro Uribe, al finalizar la ceremonia, megáfono en mano. Una semana después, la victoria del No en el plebiscito demostró que la narrativa santista había sido derribada.

\section{Conclusión}

Las confrontaciones entre las narrativas uribistas y santistas destacan la utilidad de la crisis como elemento estratégico de la comunicación de gobierno y punto de referencia dentro de los esquemas narrativos. La crisis permitió a ambas ideologías movilizar al electorado en repetidas oportunidades, así como validar tanto políticas uribistas de lucha armada contra el terrorismo como políticas santistas de diálogos con el enemigo. En ambos casos, constituyó un elemento central de las historias y sirvió como justificación del actuar gubernamental.

En este sentido, la crisis como estrategia de comunicación política resultó ser, en el caso colombiano, bastante acertada. En vez de generar desgobierno, provocó estabilidad y cohesión alrededor de la figura del héroe, al principio para apoyarlo en sus políticas de "seguridad democrática" (Uribe) y luego para apoyarlo en su decisión de buscar la paz (Santos).

Podemos resaltar, por otro lado, la coherencia que existió en cada bando entre el discurso visual conformado por símbolos en los afiches y el discurso hablado con los términos utilizados en las alocuciones. En cuanto a los actantes presentes en cada historia, evolucionan según las variaciones de las narrativas uribistas y santistas, pasando de héroes a villanos o de oponentes a ayudantes, siguiendo el mismo esquema narrativo. Las mismas estrategias discursivas se encuentran también en los discursos de ambos presidentes, movilizando los mismos frames.

A pesar de lo anterior, el ejemplo santista demostró que, más allá de los términos y de los símbolos usados, la historia debe acompañarse de un framing acertado, tanto en los discursos oficiales como en la puesta en escena de las políticas gubernamentales, para no entrar en choque con los imaginarios colectivos y generar una verdadera crisis gubernamental. La derrota del presidente Santos, ganador del Premio Nobel de la Paz, en su propio plebiscito por la paz ha sido una lección contundente.

\section{Referencias}

Actualidad Colombia. (27 de septiembre del 2016). Ceremonia completa Colombia firma la paz. Gobierno Santos, acuerdo definitivo con las FARC. [capturas de pantalla de archivo de video]. Recuperado de www.YouTube.be/gtddlp3jCUU

Afiche de la campaña "Santos Presidente 2010" [imagen]. (2010). El Confidencial. Recuperado de www. confidencialcolombia.com

Anderson, B. (2006). L'imaginaire national. Réflexions sur l'origine et l'essor du nationalisme. París: La Découverte. 
Barthes, R. (1957). Mythologies. París: Editions du Seuil.

Conozca la historia del bolígrafo con el que se firmó la paz. (24 de junio del 2016). El Heraldo. Recuperado de www.elheraldo.co/nacional/las -balas-escribieron-nuestropasadola-educación-escribiera-nuestrofuturo-santos

Echandía, C. (2006). Dos décadas de escalamiento del conflicto armado colombiano. Bogotá: Universidad Externado de Colombia.

Entman, R. (1996). Manufacturing Discord: Media in the Affirmative Action Debate. Harvard International Journal of Press/Politics, 2(4), 32-51. doi: 10.1177/1081180X97002004004

González, M. F. (2016). El poder de la palabra. Chávez, Uribe, Santos y las FARC. Bogotá: Semana Libros.

Greimas, A. J. (1970). Du sens. París: Editions du Seuil.

La firma de la paz en el Teatro Colón. (26 de noviembre del 2016). Revista Semana. Recuperado de www. semana.com/enfoqeu/articulo/ firma-del-acuerdo-de-paz-encolombia/506827

Larivaille, P. (1974). L'analyse (morpho) logique du récit. Poétique, 19, 368-388.

Miembros de las FARC, bienvenidos a la democracia. (27 de setiembre del 2016). El Tiempo. Recuperado de www.eltiempo.com/politica/procesode-paz/firma-del-acuerdo-final-depaz-con-las-farc-en-cartagena-34636

Muñiz,C.(2015). La política como debate temático o estratégico. Framing de la campaña electoral mexicana del 2012 en la prensa digital. Comunicación y sociedad, 23, 67-95. Recuperado de http://www.scielo.org.mx/scielo. php?script=sci_arttext\&pid=S0188252X2015000100004

Pardo, N. (2007). Cómo hacer análisis crítico del discurso. Una perspectiva latinoamericana. Bogotá: Universidad Nacional de Colombia.

Peirce, C. S. (1983). Studies in Logic (vol. 1). Boston: John Benjamins Publishing.

Presidente Álvaro Uribe termina su gestión con $80 \%$ de aprobación. (30 de julio del 2010). El País. Recuperado de www.elpais.com.co/colombia/ presidente-alvaro-uribe-termina-sugestion-con-80-de.aprobación.html

Real Academia Española. (2012). Definición de semiótica. Recuperado de http://dle.rae.es/srv/fetch? id $=$ XY80twH

Richard, E. (2008). Álvaro Uribe, la comunicación por la imagen. Principios de marketing político. Revista Opera, 8, 73-100. Recuperado de http://www.redalyc.org/ html/675/67500804/

Richard, E. (2014). Elecciones presidenciales en Colombia 2014: construcción de relatos de paz. En M. Batlle (Ed.), Elecciones 2014 en Colombia. Candidatos, estrategias y resultados (pp. 63-116). Bogotá: Universidad Externado de Colombia. Richard, E., y González, A. (2016). El uribismo en las elecciones 
presidenciales en Colombia, 20062014: ¿una directriz ideológica? En I. Crespo y M. Belinchón (Eds.), ¿Compiten las ideas? (pp. 35-64). Valencia: Tirant lo Blanch.

Rincón, O. (2006). Narrativas mediáticas. O cómo se cuenta la sociedad del entretenimiento. Barcelona: Gedisa.

Salmon, Ch. (2007). Storytelling. La machine à inventer des histoires et à formater les esprits. París: La Découverte.

Street, J. (2011). Mass Media, Politics and Democracy. Nueva York, NY: Palgrave.

Tankard, J. (2001). The Empirical Approach to the Study of Media Framing. En S. D. Reese, O. H. Gandy, y A. E. Grant (Eds.), Framing Public Life: Perspectives on Media and our Understanding of the Social World (pp. 215-226). Nueva Jersey, NJ: Lawrence Erlbaum Associates.

Uribe, C., y Rincón, O. (2016). Un país, muchos candidatos y un solo ganador. Campaña electoral Colombia 2014 y spots televisivos. En O. Aguilar Leyva (Coord.), El spot político en América Latina: enfoque, método y perspectivas (pp. 193-231). Universidad de Guadalajara.

Uribe Vélez, A. (2002). Afiche electoral de Uribe, elecciones presidenciales del 2002 [imagen]. Recuperado de www.alvarouribevelez.com.co

Uribe Vélez, A. (2006). Afiche electoral de Uribe, elecciones presidenciales del 2006 [imagen]. Recuperado de www.alvarouribevelez.com.co

Van Dijk, T. (1997). What is Political Discourse Analysis? En J. Blommaert, y C. Bulcaen (Eds.), Congress Political Linguistics (pp. 1152). Amberes: Political Linguistics.

Wodak, R. (2002). Aspects of Critical Discourse Analysis. Zeitschrift für Angewandte Linguistik, 36, 5-31. Recuperado de https://pdfs.seman ticscholar.org/939e/07528ca2c53445 5baa6fc1c6784138bf743.pdf 
